Pesq. Vet. Bras. 37(6):577-581, junho 2017 DOI: $10.1590 / \mathrm{S} 0100-736 \mathrm{X} 2017000600007$

\title{
Ocorrência do vírus da artrite encefalite caprina (CAEV) em cabras leiteiras produzidas em sistema intensivo confinado no estado de Minas Gerais ${ }^{1}$
}

\author{
Paula M.P. Nascimento-Penido ${ }^{2,3 *}$, André O. Penido ${ }^{2,4}$, Grazielle C.F. Galinari², \\ Marcos B. Heinemann ${ }^{5}$ e Rômulo C. Leite ${ }^{2,3}$
}

\begin{abstract}
Nascimento-Penido P.M.P., Penido A.O., Galinari G.C.F, Heinemann M.B. \& Leite R.C. 2017. [Occurrence of caprine arthritis encephalitis virus (CAEV) in dairy goats produced in an intensive confined system in the state of Minas Gerais, Brazil.] Ocorrência do vírus da artrite encefalite caprina (CAEV) em cabras leiteiras produzidas em sistema intensivo confinado no estado de Minas Gerais. Pesquisa Veterinária Brasileira 37(6):577-581. Departamento de Medicina Veterinária Preventiva, Escola de Veterinária, Universidade Federal de Minas Gerais, Av. Antônio Carlos 6627, Cx. Postal 5675, Campus da Pampulha, Belo Horizonte, MG 31270-901, Brazil.,E-mail: paulampn@gmail.com

The objective of the present study was to identify the occurrence of caprine arthritis encephalitis virus (CAEV) infection in dairy goat farms with intensive system in Minas Gerais State. Five properties were evaluated, totaling 1072 animals, being 48 males and 1024 females of different ages and breeds (Toggenburg, Saanen and Alpine). The diagnostic method used was the agar gel immunodiffusion (AGID) test, to detect antibodies anti-CAEV, which is the diagnostic test recommended by World Organization for Animal Health - OIE. The occurrence of anti-CAEV antibodies in the properties was 49.5\% (531/1072), however varied according to the farm. The anti-CAEV antibodies detection varied according to the property: Farm $1=69.6 \%(156 / 224)$; farm $2=41.5 \%$ (47/113); farm $3=40.3 \%(63 / 156)$; farm $4=24.6 \%(18 / 73)$ and farm $5=48.8 \%(247 / 506)$. Of the total sampled males, $14.5 \%$ $(7 / 48)$ were serologically positive. According to the results, there is a high occurrence rate of CAEV-seropositive animals in Minas Gerais, which has one of the largest Brazilian dairy goat herds. Therefore, it is essential to adopt strategies for CAE control, such as a routine of diagnostics tests in the properties and the separation of healthy from infected goats. The elimination of positive breeding goats in the properties is also a measure of control, because it has been shown that these are an important route of CAEV transmission in dairy farms.
\end{abstract}

INDEX TERMS: Caprine arthritis encephalitis virus, CAEV, dairy goats, confined system, Minas Gerais.

\footnotetext{
${ }^{1}$ Recebido em 31 de julho de 2015.

Aceito para publicação em 3 de fevereiro de 2017.

${ }^{2}$ Departamento de Medicina Veterinária Preventiva, Escola de Veterinária, Universidade Federal de Minas Gerais (UFMG), Av. Antônio Carlos 6627, Cx. Postal 5675, Campus da Pampulha, Belo Horizonte, MG 31270901, Brasil. *Autor para correspondência: paulampn@gmail.com

${ }^{3}$ Instituto Nacional de Ciência e Tecnologia Pecuária (INCT Pecuária), Av. Antônio Carlos 6627, Cx. Postal 5675, Campus da Pampulha, Belo Horizonte, MG 31270-901, Brasil.

${ }^{4}$ Empresa de Pesquisa Agropecuária de Minas Gerias (EPAMIG), Av. José Candido da Silveira 1647, União, Belo Horizonte, MG 31170-495, Brasil.

${ }^{5}$ Departamento de Medicina Veterinária Preventiva e Saúde Animal, Universidade de São Paulo (USP), Av. Prof. Dr. Orlando Marques de Paiva 87, Cidade Universitária, São Paulo, SP 05508-270, Brasil.
}

RESUMO-- Objetivou-se no estudo identificar a ocorrência de infecção pelo vírus da artrite encefalite caprina (CAEV) em propriedades produtoras de leite caprino com sistema intensivo no estado de Minas Gerais. Foram avaliadas cinco propriedades, localizadas em cidades distintas, totalizando 1072 animais, sendo 48 machos e 1024 fêmeas de diferentes faixas etárias, das raças Toggenburg, Alpina e Saanen. 0 método de diagnóstico utilizado foi o de imunodifusão em ágar gel (IDGA), para detecção de anticorpos anti-CAEV, por ser o diagnóstico preconizado pela Organização Mundial de Saúde Animal (OIE). A ocorrência de anticorpos anti-CAEV nas propriedades estudadas foi de $49,5 \%$ (531/1072), entretanto a mesma variou de acordo 
com a propriedade. Foram observados os seguintes resultados por propriedade: propriedade $1=69,6 \%(156 / 224)$; propriedade $2=41,5 \%$ (47/113); propriedade $3=40,3 \%$ (63/156); propriedade $4=24,6 \%(18 / 73)$ e propriedade 5 $=48,8 \%(247 / 506)$. Do total de machos avaliados, $14,5 \%$ (7/48) apresentaram sorologia positiva. De acordo com os resultados, uma alta ocorrência de animais soropositivos foi identificada no estado de Minas Gerais, o qual possui um dos maiores rebanhos de cabras leiteiras do Brasil. Portanto, salienta-se a necessidade de se adotar medidas estratégias sanitárias para o controle da CAE, como a realização de exames rotineiros nas propriedades e a separação de animais infectados dos sadios. A exclusão de reprodutores positivos nas propriedades também é uma medida de controle, pois já foi demonstrado que estes são fontes de infecção importantes.

TERMOS DE INDEXAÇÃO: Vírus da artrite encefalite caprina, CAEV, cabras leiteiras, sistema intensivo confinado, Minas Gerais.

\section{INTRODUÇÃO}

0 vírus da artrite encefalite caprina (CAEV) é um Lentivirus, pertencente à subfamília Orthoretrovirinae e família Retroviridae (ICTV 2013). 0 vírus causa uma doença crônica de evolução lenta com sinais clínicos variados. Em animais jovens, a encefalomielite é o principal quadro clínico. Já em animais adultos observa-se o aumento de volume das articulações, principalmente do carpo, pneumonia intersticial crônica e mamites severas com perda de peso progressiva e diminuição da produção leiteira (Cork \& Narayan 1980). A principal via de transmissão do CAEV nos animais ocorre principalmente durante os primeiros meses de vida, pela ingestão de leite ou colostro de cabras infectadas (Gouveia et al. 1994). Contudo, a introdução de fêmeas infectadas nos rebanhos (Lima et al. 2013); a utilização de tatuadores sem desinfecção prévia; a deficiência na higienização das ordenhadeiras; a reutilização de material descartável (Gouveia et al. 2009); a presença de gametas (Lamara et al. 2001, Paula et al. 2009, Souza et al. 2013) e/ou embriões (Lamara et al. 2002) infectados, também são potenciais disseminadores da doença, bem como o sistema de manejo empregado. Mussi (2014) descreveu que a maioria dos sistemas de produção de leite no estado de Minas Gerais é do tipo intensivo confinado, o que pode favorecer a transmissão de agentes infecciosos, como o CAEV, pelo íntimo contato entre os animais.

Poucos são os estudos referentes as perdas econômicas causadas pela CAE. Entretanto Peterhans et al. (2004) descreveram poder haver uma diminuição na produção leiteira de $10 \%$, aproximadamente. A queda na produção de leite ocorre devido à inflamação da glândula mamária, levando a uma redução na função do alvéolo mamário e lise de vários componentes do leite (Leitner et al. 2004).

Estudos soroepidemiológicos demonstram que o CAEV está disseminado em muitos estados do território nacional (Almeida et al. 2001, Pinheiro et al. 2001, Yorinori et al. 2003, Lara et al. 2005, Silva et al. 2005, Lilenbaum et al. 2007, Bandeira et al. 2009, Lima et al. 2009, 2011, 2013, Vinicius et al. 2009, Sobrinho et al. 2010, Lara et al. 2011, Martins \& Lilenbaum 2011, Sampaio Junior et al. 2011,
Rêgo et al. 2011, Veschi et al. 2011). Entretanto, a grande maioria destes estudos está concentrada na região nordeste do país, onde está a maior população caprina do Brasil, sendo 50\% desta concentrada nos estados da Bahia e Pernambuco (IBGE 2012).

De acordo com pesquisas realizadas pelo Instituto Brasileiro de Geografia e Estatística - IBGE (2012) no estado de Minas Gerais, houve aumento na população caprina leiteira, o que, consequentemente, enfatiza a importância de estudos sobre ocorrência do CAEV nas propriedades. Portanto, o objetivo do presente trabalho foi identificar a ocorrência de animais soropositivos para CAEV em propriedades produtoras de leite caprino, com sistema de criação intensivo confinado, no estado de Minas Gerais.

\section{MATERIAL E MÉTODOS}

Foram analisadas amostras de soro de 1072 caprinos, sendo 1024 fêmeas com idade entre seis meses e nove anos e 48 machos na mesma faixa etária, das raças Saanen, Alpina e Toggenburg.

As cabras encontravam-se em cinco propriedades com sistema de criação intensivo confinado, estando localizadas em três regiões produtoras de leite distintas no estado de Minas Gerais, sendo selecionadas por serem as propriedades maiores e mais tradicionais na produção leiteira caprina, onde propriedade 1 possuía 224 cabras, propriedade $2=113$ cabras, propriedade $3=156$ cabras, propriedade $4=73$ cabras e propriedade $5=506$ cabras. As cinco propriedades utilizavam pelo menos uma estratégia de controle para a CAE (Quadro 1).

As cabras eram mantidas em sistema intensivo confinado de produção e separadas de acordo com o "status" de produção (pluríparas lactantes, pluríparas não lactantes e nulíparas), assim como os reprodutores.

Todas as cabras presentes nas cinco propriedades foram submetidas ao diagnóstico. 0 sangue foi coletado em tubos de $10 \mathrm{~mL}$, através de venopunção da jugular externa com o auxílio do sistema Vacutainer ${ }^{\circledR}$ sem EDTA, após prévia limpeza da região com algodão embebido em álcool $70 \%$. Logo após a coleta, o sangue foi centrifugado (1200xg/ $10 \mathrm{~min}$ ) e os soros oriundos das amostras foram armazenados em microtubos de $1,5 \mathrm{~mL}$ e mantidos congelados $\left(-20^{\circ} \mathrm{C}\right)$ até o momento da realização do diagnóstico sorológico.

O diagnóstico utilizado foi o teste de imunodifusão em ágar gel (IDGA) comercial (Biovetech ${ }^{\circledR}$, Recife - Brasil). 0 teste foi utilizado por ser o preconizado pela OIE. As amostras de soro foram distribuídas em três poços alternados no volume de $30 \mu \mathrm{L}$. Em outros três poços, também alternados, adicionou-se os soros controles, no volume de $10 \mu \mathrm{L}$ e no centro da roseta, o antígeno foi adiciona-

Quadro 1. Medidas estratégicas para controle da CAE adotadas nas propriedades

\begin{tabular}{cccccccc}
\hline Prop. & \multicolumn{6}{c}{ Medidas de controle } \\
\cline { 2 - 7 } & $\begin{array}{l}\text { Separação } \\
\text { por idade }\end{array}$ & $\begin{array}{c}* \text { Linha de } \\
\text { ordenha }\end{array}$ & $\begin{array}{c}* * \text { Tratamento } \\
\text { térmico }\end{array}$ & $\begin{array}{c}\text { Mamadeira } \\
\text { individual }\end{array}$ & $\begin{array}{c}* * * \text { Diag. } \\
\text { sorológico }\end{array}$ & $* * *$ MN \\
\hline 1 & - & - & - & - & - & - \\
2 & - & - & + & - & - & - \\
3 & + & - & - & - & - & - \\
4 & + & + & + & + & + & + \\
5 & - & - & + & - & - & +
\end{tabular}

$\overline{\text { Prop }=\text { Propriedade }}$ *Linha de ordenha e higienização correta do equipamento utilizado; ${ }^{* *}$ Tratamento térmico do leite e colostro; ${ }^{* * *}$ Diagnóstico sorológico realizado a cada seis meses. ${ }^{* * * *}$ Monta natural com reprodutores negativos para CAEV. 
do. A primeira leitura foi realizada após 48 horas de incubação e foi confirmada após 72 horas de incubação, com o auxílio de luz artificial proveniente de uma câmara escura. Foram considerados positivos os soros que formaram uma linha de precipitação (linha de identidade) nas regiões de contato antígeno-anticorpo.

0 método de análise estatística utilizado foi o Teste de Fisher $(\mathrm{p}<0,05)$.

\section{RESULTADOS E DISCUSSÃO}

Todas as propriedades possuíam histórico da doença confirmado e alguns animais demonstravam sinais clínicos sugestivos de CAE, como aumento da região do carpo e nódulos nas glândulas mamárias, relacionados com quadros de artrite e mamite. Entretanto, não foram observados quadros de encefalomielite em nenhuma das propriedades avaliadas.

A ocorrência de caprinos com anticorpos anti-CAEV nas cinco propriedades avaliadas foi de 49,5\% (531/1072), em fêmeas de idades entre seis meses a nove anos de idade. Esta ocorrência é superior à demonstrada pela literatura consultada: Almeida et al. $2001=13,4 \%$ (215/1605); Pinheiro et al. $2001=1 \%(40 / 4019)$; Yorinori et al. 2003 $=0,3 \%$ (4/1294); Lara et al. $2005=15,5 \%$ (30/199), Silva et al. $2005=2,71 \%(5 / 184)$; Lilenbaum et al. $2007=$ 14,2\% (79/541); Madureira et al. $2007=34,9 \%$ (96/275); Bandeira et al. $2009=14,5 \%(87 / 600)$; Lima et al. $2009=$ $0,1 \%$ (0/150); Vinicius et al. $2009=22,8 \%$ (13/57); Sobrinho et al. $2010=2,7 \%$ (23/843); Lara et al. $2011=15,5 \%$ (30/199); Lima et al. $2011=0,87 \%$ (6/693); Sampaio Junior et al. $2011=4,2 \%$ (20/480); Rêgo et al. $2011=0.97 \%$ (7/723); Veschi et al. $2011=12,05 \%(135 / 1120)$; Lima et al. $2013=0,29 \%(2 / 663)$. Todos os trabalhos citados utilizaram o IDGA como método de diagnóstico, porém, referem-se a sistemas de produção extensivo ou semi-intensivo, diferindo das propriedades avaliadas no estudo.

Os resultados obtidos demonstraram que a ocorrência de animais soropositivos para CAEV é elevada em criações de caprinos leiteiros criados em sistema de produção intensivo confinado no Estado de Minas Gerais. Entretanto, a ocorrência da soropositividade variou de acordo com a propriedade: propriedade $1=69,6 \%(156 / 224)$; propriedade $2=41,5 \%$ (47/113); propriedade $3=40,3 \%$ (63/156); propriedade $4=24,6 \%(18 / 73)$ e propriedade $5=48,8 \%(247 / 506)$ (Fig.1). A ocorrência de animais soropositivos para CAEV na propriedade 1 diferiu $(\mathrm{p}<0,05)$ das propriedades 2,3 , 4 e 5, assim como a ocorrência de animais soropositivos para CAEV na propriedade 4 diferiu $(\mathrm{p}<0,05)$ das propriedades 2,3 e 5 , de acordo com o Teste de Fisher.

Os estudos realizados no estado de Minas Gerais, demonstraram uma baixa ocorrência quando comparado com os resultados identificados: Yorinori et al. $2003(0,3 \%$ $=4 / 1294)$ e Vinicius et al. 2009 (22,8\% = 13/57). Entretanto, ambos trabalhos utilizaram animais sem raça definida e em sistema extensivo de criação.

A prevalência do CAEV é mais alta em animais puros do que em animais mestiços ou sem raça definida (Melo \& Franke 1997, Almeida et al. 2001, Sampaio Junior et al. 2011), bem como em sistema intensivo confinado. Este tipo

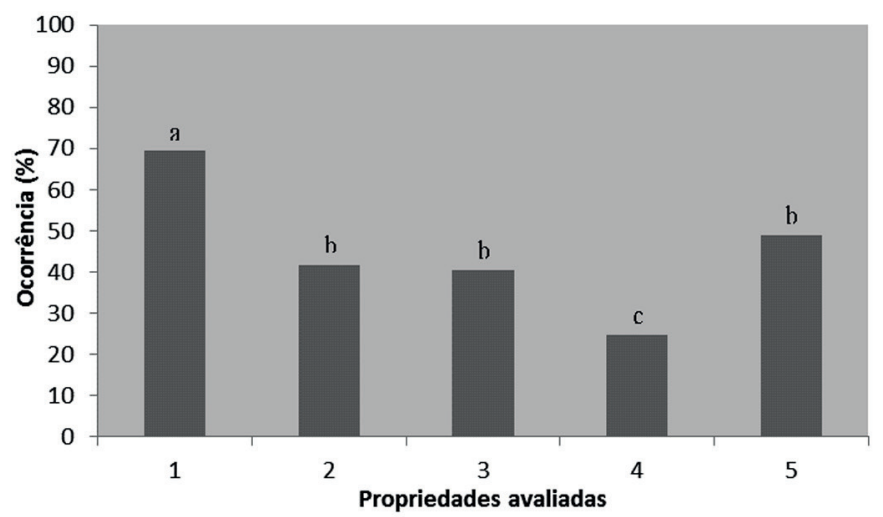

Fig.1. Ocorrência de animais soropositivos para CAEV em propriedades produtoras de leite caprino no Estado de Minas Gerais (letras diferentes, diferem-se entre si $(\mathrm{p}<0,05)$.

de sistema funciona como um dos fatores que aumentam a frequência de infecção dos animais, devido ao estreito contato entre os animais em rebanhos leiteiros com criação intensiva confinada (Yorinori et al. 2003, Lima et al. 2013, Mussi 2014). Esse fato pode explicar essa divergência nos resultados, uma vez que todas as propriedades avaliadas possuíam sistema intensivo confinado e todos os animais eram puros. Martins \& Lilenbaum (2011) ao trabalharem com animais puros criados em um sistema de criação intensivo confinado, obtiveram uma ocorrência de 40,73\% (101/248) no Estado do Rio de Janeiro, dados mais próximos aos encontrados neste estudo.

Sinas clínicos relacionados à doença, como aumento do carpo causando problemas de locomoção dos animais, mamites severas com nodulações nas glândulas mamárias e pneumonias com secreções purulentas foram observadas em todas as propriedades, entretanto esses achados não foram avaliados isoladamente.

O diagnóstico sorológico deve ser empregado a cada seis meses, afim de identificar os animais positivos e separá-los do restante do rebanho, ou mesmo eliminá-los (Pinheiro et al. 2001). Esta não é uma estratégia empregada pela maioria dos produtores. Apenas a propriedade 4 realizava este tipo de diagnóstico e empregava o tratamento térmico do leite e colostro oferecidos aos recém-nascidos em mamadeiras individualizadas (Quadro 1). A separação dos animais positivos e por idade também eram estratégias utilizadas, podendo justificar a menor ocorrência de animais soropositivos $(24,6 \%)$ nesta propriedade, entre as cinco avaliadas.

As propriedades 1, 2, 3, e 5 empregavam algum tipo de estratégia de controle da CAE isoladamente ou às vezes duas estratégias, tais como: separação dos animais por idade; ou tratamento térmico do leite; ou banco de colostro; ou linha de ordenha para animais com sinais clínicos; e higienização das ordenhadeiras (Quadro 1). Por outro lado, todas elas reutilizavam materiais descartáveis e não higienizavam os tatuadores, demonstrando a necessidade de adoção de medidas de controle e prevenção para a doença.

Do total de machos avaliados, 14,5\% (7/48) apresentaram sorologia positiva para CAEV. O CAEV é liberado no sêmen de forma intermitente (Cruz et al. 2009) e indepen- 
dentemente da época em que ocorre a soroconversão (Paula et al. 2009), sendo uma provável fonte de transmissão do vírus. A monta natural e a inseminação artificial eram empregadas nas propriedades 1, 2, 3 e 5. Porém, não era feito o diagnóstico para CAE nos reprodutores utilizados, os quais eram do próprio rebanho ou muitas vezes eram oriundos de empréstimos de reprodutores entre produtores, com o objetivo de melhorar a genética. Somente a propriedade 4 utilizava a inseminação artificial e monta natural com reprodutores soronegativos para CAEV.

A desinformação dos produtores em relação à CAE e às vias de transmissão da mesma, assim como a falta de técnicos qualificados para a implementação de medidas estratégicas de prevenção e controle da doença são fatores determinantes para o insucesso de um programa de controle sanitário da CAE.

A alta ocorrência da CAE em sistemas de produção de leite caprino tem um impacto negativo, afetando em até $10 \%$ a produção leiteira (Peterhans et al. 2004). Logo, é de extrema importância que estratégias de prevenção e controle sejam implementadas nos rebanhos, tais como: testes sorológicos a cada seis meses, com a separação de animais positivos e negativos; tratamento térmico do leite oferecido aos recém nascidos e banco de colostro oriundo de cabras comprovadamente negativas; desinfecção de utensílios comuns, como tatuadores e teteiras das ordenhas; inutilização de materiais descartáveis; utilização de reprodutores negativos em cabras negativas e a utilização da inseminação artificial em cabras positivas.

\section{CONCLUSÃO}

No presente trabalho, uma alta ocorrência de animais soropositivos para CAEV em rebanhos caprinos leiteiros que utilizavam sistema de produção intensivo confinado no Estado de Minas Gerais foi observada, o que pode ter um impacto negativo direto na produção leiteira, podendo causar grandes perdas econômicas. Desta forma, salienta-se a necessidade de implementação de programas de controle e prevenção da doença.

Agradecimentos.- Gostaríamos de agradecer ao CNPq pelo financiamento do projeto (553989/2010-4); INCT Pecuária pelo apoio durante toda a realização do estudo e aos proprietários que nos permitiram coletar as amostras sanguíneas.

\section{REFERÊNCIAS}

Almeida M.G.A.R., Anunciação A.V.M., Figueiredo A., Martinez T.C.N. \& Laborda S.S. 2001. Dados sorológicos sobre a presença e distribuição da artrite-encefalite caprina (CAE) no Estado da Bahia. Revta Bras. Saúde Prod. Anim. 3:78-83.

Bandeira D.A., Castro R.S., Azevedo E.O., Melo L.S.S. \& Melo C.B. 2009. Seroprevalence of caprine arthritis-enceplalitis vírus in goats in the Cariri region, Paraiba state, Brazil. Vet. J. 180:399-401.

Cork L.C. \& Narayan O. 1980. The pathogenesis of viral leukoencephamyelitis-arthritis of goats. Lab. Invest. 42:596-602.

Cruz J.C.M., Gouveia A.M.G., Souza K.C., Braz G.F., Teixeira B.M., Heinemann M.B., Leite R.C., Reis J.K.P., Pinheiro R.R. \& Andrioli A. 2009. Caprine arthritis-encephalitis virus (CAEV) detection in semen of endangered goat breeds by nested polymerase chain reaction. Small Rumin. Res. 85:149152.

Gouveia A.M.G., Santa Rosa J., Pinheiro R.R., Alves F. \& Souto Vidal C.E.
1994 Implantação de um programa de controle da CAEV em sistemas epidemiológicos distintos. Anais 23ํㅡㄹ Congresso Brasileiro de Medicina Veterinária, Recife, p.102.

Gouveia A.M.G., Guimarães A.S., Haddad J.P.A., Abreu C.P., Leite R.C., Heinemann M.B., Lage A.P., Cruz J.C.M. \& Carmo F.B. 2009. Características zoosanitárias da caprinocultura leiteira em Minas Gerais, Brasil. Disponível em <http.www.accomig.com.br> Acesso em 20 jul. 2015.

IBGE 2012. Produção da Pecuária Municipal. Vol.40. Instituto Brasileiro de Geografia e Estatística. 68p. Disponível em ftp://ftp.ibge.gov.br/Producao_Pecuaria/Producao_da_Pecuaria_Municipal/2012/ppm2012.pdf. Acesso em 15 jul., 2015.

ICTV 2013. International Committee of Taxonomy of Viruses. Disponível em <https://talk.ictvonline.org/> Acesso em 4 jan. 2015.

Lamara A., Fieni F., Mselli-Lakhal L., Tainturir D. \& Chebloune Y. 2001. Efficient replication of caprine arthritis encephalitis virus in goat granulosa cells. Virus Res. 1201:165-172.

Lamara A., Fieni F., Mselli-Lakhal L., Chatagnon G., Bruyas J.F., Taainturier D., Battut I., Fornazero C. \& Chebloune Y. 2002. Early embryonic cells from in vivo-produced goat embryos transmit the caprine arthritis-encephalitis virus (CAEV). Theriogenology 58:1153-1163.

Lara M.C.C.S.H., Birgel Junior E.H., Gregory L. \& Birgel E.H. 2005. Aspectos clínicos da artrite-encefalite dos caprinos. Arq. Bras. Med. Vet. Zootec. $57: 737-740$

Lara M.C.C.S.H., Villalobos E.M.C., Cunha E.M.S., Chiebao D., Gabriel F.H., Paulin L.M., Castro V., Nassar A.F., Okuda L., Nogueira A.H.C., Valadas S., Federsoni L.S., Lucchese Filho A., Felicio F.A. \& Cardoso M.V. 2011. Inquérito sorológico de lentiviroses de pequenos ruminantes (Maedi-Visna e artrite-encefalite caprina) no estado de São Paulo. Braz. J. Vet. Res. Anm. Sci. 50:18-25.

Leitner G., Merin U., Silanikove N., Ezra E., Chaffer M., Gollop N., Winkler M., Glickman A. \& Saran A. 2004. Effect of subclinical intramammary infection on somatic cells counts, NAGase activity and gross composition of goats milk. J. Dairy Res. 71:311-315.

Lilenbaum W., Souza G.N., Ristow P., Moreira M.C., Fraguas S., Cardoso V.D. \& Oelemann W.M.R. 2007. A serological study on Brucella abortus, caprine-encephalitis vírus and Leptospira in dairy goats in Rio de Janeiro, Brazil. Vet. J. 173:408-412.

Lima C.C.V., Souza T.S., Martinez P.M., Costa J.N., Almeida M.G.A.R., Anunciação A.V.M. \& Pinheiro R.R. 2009. Prevalência sorológica da artrite-encefalite caprina em rebanhos caprinos do município de Juazeiro, Bahia, Brasil. Anais VIII Congresso Basileiro de Buiatria, Belo Horizonte, MG. Ciênc. Anim. Bras. 36(Supl.1):516-524.

Lima C.C.V., Costa J.N., Martinez P.M., Lima C.C.V., Araújo B.R., Costa Neto A.O., Anunciação A.V.M., Almeida M.G.A. R. \& Pinheiro R.R. 2011. Seroepidemiological survey for Brucella ovis infection in sheep flocks of semi-arid region in Bahia State, Brazil. Vet. Zootec. 18:697-700.

Lima C.C.V., Costa J.V., Souza T.S., Martinez P.M., Costa Neto A.O., Anunciação A.V.M., Almeida M.G.A.R., Araújo B.R. \& Pinheiro R.R. 2013. Inquérito soroepidemiológico do lentivírus caprino e perfil das criações de caprinos na região do Baixo Médio São Francisco (BA). Arqs Inst. Biológico, São Paulo, 80:288-296.

Martins G. \& Lilenbaum W. 2011. Possible effect of cooperatives in the control of caprine arthritis-encephalites in Rio de Janeiro, Brazil. Vet. Rec. 9:169.

Madureira K.M. \& Gomes V. 2007. Prevalência da artrite encefalite caprina (CAE) em propriedades leiterias do Estado de São Paulo. Revta Ciênc. Vet. 5:86-90.

Melo A.C.M. \& Franke C.R. 1997. Soroprevalência da infecção pelo vírus da artrite-encefalite caprina (CAEV) no rebanho de caprinos leiteiros da região da grande Fortaleza, Ceará, Brasil. Ciência Rural 27:113-117.

Moura Sobrinho P.A., Ramos T.R.R., Fernandes C.H.C., Campos A.C., Costa L.M. \& Castro R.S. 2010. Prevalência e fatores associados à infecção por lentivírus de pequenos ruminantes em caprinos no estado do Tocantins. Ciênc. Anim. Bras. 11:117-124.

Mussi J.M.S. 2014. Perfil das propriedades comerciais com caprinos em Minas Gerais e sua relação com a soroprevalência do lentivírus de pe- 
quenos ruminantes. Dissertação de Mestrado, Universidade Federal de Minas Gerais, Belo Horizonte. 83p.

Paula N.R.O., Andrioli A., Cardoso J.F.S., Pinheiro R.R., Sousa F.M.L., Souza K.C., Alves F.S.F., Campello C.C., Ricarte A.R.F. \& Teixeira M.F.S. 2009. Profile of the caprine arthritis-encephalitis virus (CAEV) in blood, semen from bucks naturally and experimentally infected in the semi-arid region Brazil. Small Rumin. Res. 85:27-33.

Peterhans E., Greenland T., Badiola J., Harkiss G., Bertoni G., Amorena B., Eliaszewicz M., Juste R.A., Krassnig R., Lafont J.P., Lenihan P., Pétursson G., Pritchard G., Thorley J., Vitu C., Mornex J.F. \& Pépin M. 2004. Routes of the transmission and consequences of small ruminant lentiviruses (SRLs) infection and eradication schemes. Vet. Res. 35:257-274.

Pinheiro R.R., Gouveia A.M.G. \& Alves F.S.F. 2001. Prevalência da infecção pelo vírus da artrite encefalite caprina no estado do Ceará, Brasil. Ciênc. Rural 31:449-454.

Rêgo W.M.F., Paula N.R.O., Dinis B.L.M. \& Clementino D.C. 2011. Soroprevalência do vírus da artrite encefalite caprina (CAEV) nas cidades de Iatueira, Floriano, São Francisco do Piauí e São José do Peixe, no sul do Estado do Piauí. Anais XXI Seminário de Iniciação Científica, Teresina, PI, 1:326.

Sampaio Junior A., Batista M.C.S., Cruz M.S.P., Silva R.A.B., Bona Nascimen- to C. \& Werneck G.L. 2011. Prevalência da infecção por lentivírus de pequenos ruminantes em caprinos em Teresina, Piauí. Arq. Bras. Med. Vet. Zootec. 63:757-760.

Silva J.S., Castro R.S., Melo C.B. \& Feijó F.M.C. 2005. Infecção pelo vírus da artrite encefalite caprina no Rio Grande do Norte. Arq. Bras. Med. Vet. Zootec. 57:726-731.

Souza K.C., Pinheiro R.R., Santos O.S., Brito R.L.L., Rodrigues A.S., Sider L.H., Paula N.R.O., Avila A.A., Cardoso J.F.S. \& Andrioli A. 2013. Transmission of the caprine arthritis-encephalitis virus through artificial insemination. Small Rumin. Res. 109:193-198.

Veschi J.L., Martins R.J., Zafalon L.F., Costa M.M., Ramos E.M., Pixoto R.M. \& Castro R.S. 2011. Soroprevalência da CAE em caprinos leiteiros do território do Sisal, Bahia. Anais II Encontro Nacional de Defesa Sanitária Animal (Endesa). CRMV-SP, p.32.

Vinicius M.A.S., Salaberry S.R.S., Pinheiro R.R., Oliveira V.S.A., Andrioli A. \& Bombonato N.G. 2009. Ocorrência da infecção pelo vírus da artrite encefalite caprina em Patos de Minas, Minas Gerais, Brasil. Anais 33응 Congresso Brasileiro de Medicina Veterinária, Porto Seguro, BA, 61:89.

Yorinori E.H., Pinheiro R.R., Gouveia A.M.G., Nunes M.A.B.C. \& Haddad J.P.A. 2003. Estudo epidemiológico da artrite encefalite caprina nas regiões norte e nordeste de Minas Gerais. Revta Univ. Rural 23:259-260. 